\title{
Modeling urban growth in Kigali city Rwanda
}

\author{
G. Nduwayezu ${ }^{1}$, R. Sliuzas ${ }^{2}$, M. Kuffer ${ }^{3}$ \\ ${ }^{1}$ University of Rwanda, School of Science and Technology, Department of Civil, Environmental and Geomatics Engineering. \\ ${ }^{23}$ University of Twente, Faculty of Geo-Information science and earth observation, Enschede, The Netherlands. \\ $\underline{\text { nduwayezugilbert@gmail.com }}{ }^{1}, \underline{\text { r.sliuzas@utwente.nl }}{ }^{2}, \underline{\text { m.kuffer@utwente.nl }}{ }^{3}$.
}

\begin{abstract}
The uncontrolled urban growth is the key characteristics in most cities in less developed countries. However, having a good understanding of the key drivers of the city's growth dynamism has proven to be a key instrument to manage urban growth. This paper investigates the main determinants of Kigali city growth looking at how they changed over time and also how they contributed to the city change through different Logistic Regression models. First, it analyses the spatio-temporal growth of Kigali city through a consistent set of land cover maps of during the period 1987, 1999, 2009 and 2014. Second, after building a Logistic Regression model; the main drivers of Kigali city growth are identified. Third to characterize the future pattern of the city in next 26 years, three scenarios are performed, i.e. urban growth model for expansion (normal growth) and two densification (zoning implication) i.e. strict and moderate scenarios. Logistic Regression Models probability maps for the three scenario were evaluated by means of Kappa statistic, ROC value and the percentage of 2014 built-up land cover predicted. The results indicated that new urban developments in Kigali city tend to be close to the existing urban areas, further from the Center Business District (CBD) and wetlands but on low slope sites. Three scenarios built have patterns characterized by a strong compactness of urban densities. However, all three models tend to exclude urban units in the Eastern-Southern part of the city. The three models tend to exclude urban units in the EasternSouthern part of the city compared to the proposed zoning maps. Models results in 2040 indicate that the city trend will be doubled if the current trend rate continues. Models built, will help to better understand the dynamics of built-up area and guide sustainable urban development planning of the future urban growth in Kigali city.
\end{abstract}

Keywords-Urban growth, GIS, Remote Sensing, Logistic Regression modeling, Kigali city, Rwanda 


\section{Introduction}

\subsection{Urban developments and planning policy in Kigali city}

In the 21st century, rapid urbanization and urban growth have been one of the crucial issues of global change that affect the physical dimension of cities. In the past few decades, this has drastically accelerated in many developing countries. UN-HABITAT (2011) reported that 3.6 billion of the world's population (52\%) was urban dwellers. Globally, the level of urbanization is expected to rise to $67 \%$ in 2050 . In the less developed regions, the proportion of the urban area population is expected to rise from $47 \%$ in 2011 to $64 \%$ in 2050. In Africa alone the urban population is expected to triple from 414 million in 2011 to 1.2 billion 2050 (UN-HABITAT, 2011). This may lead to higher urbanization rates in Africa than in other regions of the world, with urban land cover growth of more than 12-fold between 2000 and 2050 in subSaharan Africa (Mohan, 2010). In Kigali city, rapid urbanization and urban growth are recognized facts (Civco et al., 2005). Socioeconomic and demographic trends, such as population growth, industrialization, land consumption and infrastructural development, have impacted on the state of the Kigali city expansion (REMA, 2013). Kigali city's current planning approach requires more data integration, multi-disciplinary and composite analysis regarding its urban expansion, and need faster and more precise information for all decision-makers and stakeholders (Aibinu, 2001). In recent years, the Government of Rwanda has elaborated and implemented a series of urbanization plans, policies and regulations to orient Kigali city growth toward a sustainable city (Manirakiza, 2012). Rwanda Vision 2020, National Urban Housing Policy (2008), National Land Use Planning (2012), Kigali City Conceptual Master Plan (2008) and Kigali city Master plan (2013) are among the key policies that have been elaborated as a tool for making the Kigali city's future more sustainable (Surbana, 2012). However, implementation of these policies is still in process, it appears that the city growth pace remains. In addition, factors that are behind that growth are still undisclosed (Manirakiza, 2012). A better understanding of those factors that are governing the city growth is needed for a sustainable future development of the Kigali City. Some attempts have been undertaken in quantifying urban growth of Kigali City (Civco et al., 2005; Edaw, Architecture, Tech, ERA, \& Borders, 2007), but the main drivers controlling Kigali City growth are still undetermined. Logistic Regression Model (LRM) has been proven to be a suitable approach for urban growth modeling in such kind of fast growing cities (Huang et al., 2009). This study explores the capability of freely available Remote Sensing Landsat archived imageries that have been confirmed to monitor the urban growth pattern (Griffiths et al., 2010). LRMs developed allow the creation of spatially detailed urban expansion forecasts for 2025 and 2040 for Kigali City, that were compared to the proposed 2025 and 2040 zoning plans. 


\subsection{Logistic Regression in urban growth modeling}

Based on the temporal scale, there are two modeling approaches according to their process of land cover/use change simulation: micro- level and macro level modeling (Hu and Lo, 2007; Hu, 2004; Pullar and Pettit, 2003). Micro- level models (are called also rule - / process-based models) attempt to analyze patterns of land cover/use change as the aggregate outcome of many disparate individual land use decisions across space, of which there is Cellular Automata (CA) which has a great capability to handle temporal dynamics (Hu and Lo, 2007). CA focuses on micro-spatial pattern, but using it is difficult to reflect macro-changes affected by social and economic factors (Hu and Lo, 2007). Moreover, it is difficult to define and implement appropriate rules for instance in multiple phenomena case studies (O'Sullivan and Torrent, 2000). Macro-level models also called empirical-statistic models are deterministic models which apply strict cause-effects relationships within a system to be modeled (Koomen and Stillwell, 2007). LRM, one of the empirical-statistical methods estimates the probability that a particular event will occur where it analyzes relationships between a dichotomous dependent variable and metric or dichotomous independent variable (Pullar and Pettit, 2003). This empirical statistical approach can make a vital contribution in urban growth modeling studies (Lesschen et al., 2005). LRM has shown its high capability to capture the probability of new urban developments that will take place in the future using less computer resources ( $\mathrm{Hu}$ and $\mathrm{Lo}, 2007 ; \mathrm{Hu}, 2004)$. Many authors claimed that LRM has a strong capability to not only incorporate biophysical influence (slope, land use/cover, transport, zoning) but also demographic and social variables to better understand human forces' ability in urban growth pattern (Hu and Lo, 2007). Nong and Du (2011) assured that by less computation resources, LRM calibration can allow multi-scale (different moving window sizes) simulations. Fundamentally, LRM is simple to interpret Field (2013); Moore. et al. (2009), suitable approach to evaluate critical areas for future urban developments (informal settlement proliferation or urban growth; i.e. areas that will be highly urbanized and not) Dubovyk et al. (2011); Duwal (2013) and to assess the impact of macro-level changes (e.g major roads, built-up areas, etc.) (Lesschen et al., 2005). LRM overcomes CA barriers. Where it is difficult in CA model, LRM integrates spatial and socioeconomic and demographic factors in an urban growth perspective. In addition, the computation requirements for LR models are not as intensive as for example for CA models. Eventually, the input data requirements are relatively easy to fulfil, making LR especially useful in developing countries where reliable data is often scarce (Arsanjani et al., 2013). LRM coupled with GIS and RS has been claimed to be a very effective tool for land cover/use change modeling, due to its explanatory power and spatial explicitness (Dendoncker et al., 2007). LRM provides an opportunity to analyze future development patterns based on the trends observed in the past, and it helps to quantify 
the contribution of the individual forces that drive land cover/use change, and thus provides the information needed to properly calibrate land cover/use change and urban growth models (Dendoncker et al., 2007). LRM has been applied in the lot of urban growth studies (Arsanjani et al., 2013; Dendoncker et al., 2007; Dubovyk et al., 2011; Duwal, 2013; Hu and Lo, 2007; Munshi et al., 2014; Nong and Du, 2011). For example, LRM has been applied in some East African cities by Abebe (2013) in Kampala, Uganda and Abebe (2011) in Dar es Salaam modeling urban growth and informal settlement development. In above studies the authors used one overall LR model to identify driving forces. The aim of the current study is to build different LR models to analyze the main determinants of Kigali city growth looking at how they changed over time and also how they contributed to the city change. Understanding and quantifying the spatial-temporal dynamics of urban growth and its drivers can help to better understand the dynamics of built-up area and guide sustainable urban development planning of the future urban growth in Kigali city.

\section{Materials and methods}

\subsection{Study area}

Kigali city is situated between $29^{\circ} 43^{\prime} 0^{\prime}$ ' $\mathrm{E}$ and $29^{\circ} 44^{\prime} 0^{\prime \prime} \mathrm{E}$ of Longitude and $2^{\circ} 35^{\prime} 0^{\prime}$ 'S and 2 $37^{\circ} 0^{\prime}$ 'S of Latitude. The city is built on hilly landscape sprawling across four ridges, separated from each other by large valleys in between. Kigali city is one among five provinces which composes the country of Rwanda. Kigali city is surrounded by the Northern Province on the North, Eastern Province on the East and South and Southern Province on the West. The elevation of the lower part is roughly $1400 \mathrm{~m}$ and the higher hills are at over $1845 \mathrm{~m}$ above the sea. The highest hill is Mount Kigali with $1850 \mathrm{~m}$ of latitude (see Figure 1). Over time, the city of Kigali has evolved by leaps from one hilltop to another (Michelon, 2009). This discontinuity is due to various constraints, namely the existence of flood plains, swamp and steep slopes. The settlements were mostly developed on gently sloping hillsides and on flattened hilltops. Nowadays Kigali city is subdivided into three districts; Gasabo, Kicukiro and Nyarugenge. Those 3 districts have 35 sectors, subdivided also into 161 cells. The cells also comprise a total number of 1061 imidugudu literally villages (REMA, 2013).

Kigali city is among fastest growing cities in Africa with a strong population growth with average annual growth rate of $4.0 \%$ (NISR, 2012). Kigali has grown from a population of 6000 people in 1962 (when Rwanda gained its independence) to over 1 million inhabitants today. Such an increase of population in Kigali city was a result of the big migration of people from rural areas for employment and business opportunities and also returning refugees after 1994. 
Figure 1: The location and topography of the study area.

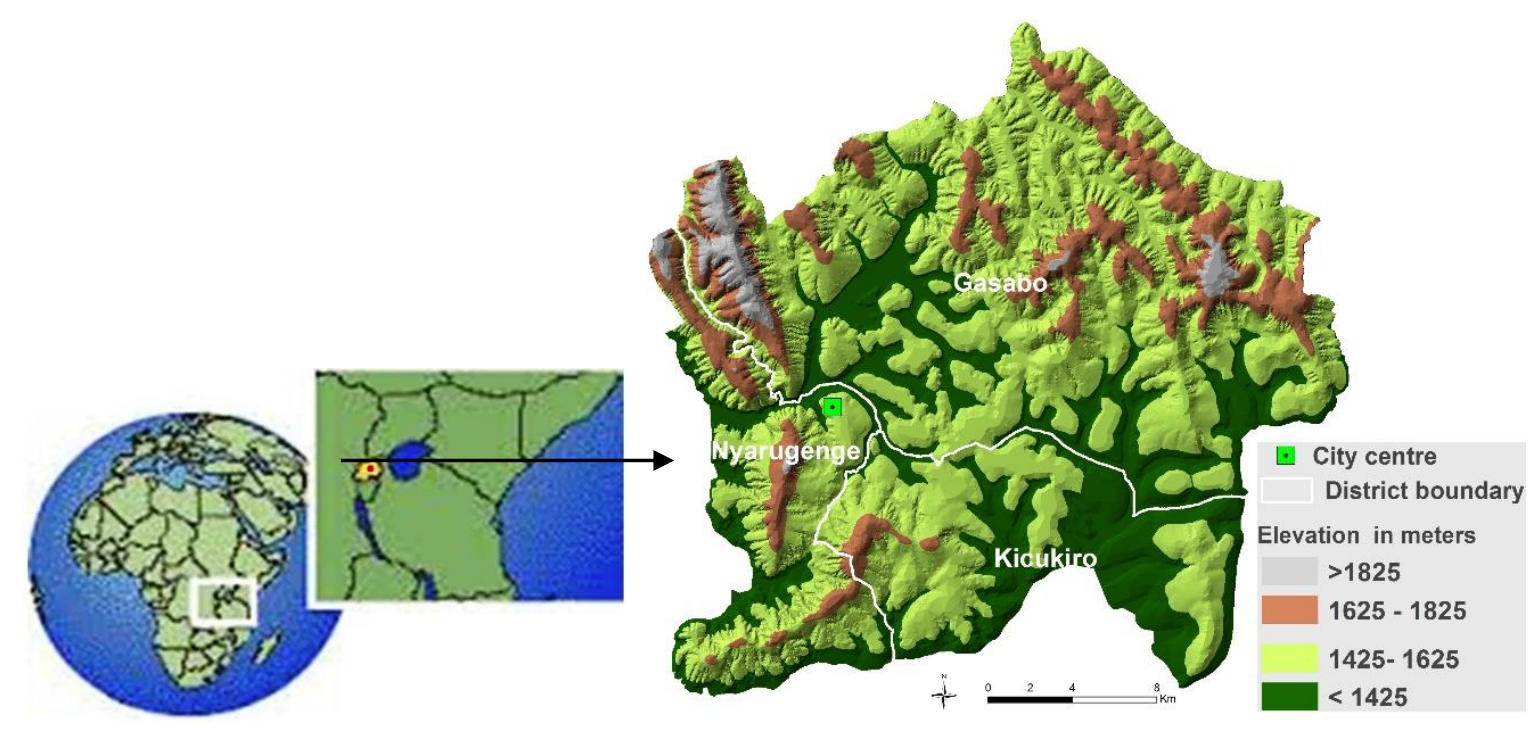

\subsection{Data sources}

The data used in this study were coming from different sources and institutions refer to Table 1 .

Table 1: Remote sensing data.

\begin{tabular}{|c|c|c|c|c|c|}
\hline Type of Data & Time period & Source & Resolution & Projection & Purpose \\
\hline Landsat TM & $\begin{array}{l}\text { 1987-05- } \\
\text { Febuary }\end{array}$ & USGS & $30 \mathrm{~m}$ & $\begin{array}{l}\text { WGS_1984_UT } \\
\text { M_Zone_36N }\end{array}$ & \multirow{4}{*}{$\begin{array}{l}\text { Landsat imageries } \\
\text { were used for } \\
\text { preparing land cover } \\
\text { maps. }\end{array}$} \\
\hline Landsat TM & 1999-08-July & USGS & $30 \mathrm{~m}$ & $\begin{array}{l}\text { WGS_1984_UT } \\
\text { M_Zone_36N }\end{array}$ & \\
\hline Landsat TM+ & 2009-25-June & USGS & $30 \mathrm{~m}$ & $\begin{array}{l}\text { WGS_1984_UT } \\
\text { M_Zone_36N }\end{array}$ & \\
\hline Landsat OLI & $\begin{array}{l}\text { 2104-14- } \\
\text { January }\end{array}$ & USGS & $30 \mathrm{~m}$ & $\begin{array}{l}\text { WGS_1984_UT } \\
\text { M_Zone_36N }\end{array}$ & \\
\hline $\begin{array}{l}\text { Aerial } \\
\text { photography }\end{array}$ & 2008 & RNRA & $0.25 \mathrm{~m}$ & GCS_ITRF_2005 & \multirow{3}{*}{$\begin{array}{l}\text { High resolution } \\
\text { images were used for } \\
\text { verification of training } \\
\text { sample sets. }\end{array}$} \\
\hline $\begin{array}{l}\text { Kigali city Topo } \\
\text { map }\end{array}$ & 1986 & $\begin{array}{l}\text { ITC/ } \\
\text { RNRA }\end{array}$ & $4 \mathrm{~m}$ & $\begin{array}{l}\text { WGS_1984_UT } \\
\text { M_Zone_36N }\end{array}$ & \\
\hline $\begin{array}{l}\text { Kigali city } \\
\text { Cadastral map }\end{array}$ & 1994 & $\begin{array}{l}\text { Internet } \\
1\end{array}$ & $1: 10000$ & $\begin{array}{l}\text { No projection } \\
\text { (Georeferenced) }\end{array}$ & \\
\hline
\end{tabular}




\begin{tabular}{lllll} 
Quickbird & 2004 & CGIS- & $1 \mathrm{~m}$ & WGS_1984_UT \\
image & & Butare & & M_Zone_36N \\
Google earth & 2004 & ITC & $0.9 \mathrm{~m}$ & D_WGS_1984 \\
Google earth & 2005 & ITC & $0.9 \mathrm{~m}$ & D_WGS_1984 \\
Google earth & 2014 & ITC & $0.9 \mathrm{~m}$ & D_WGS_1984 \\
\hline \hline
\end{tabular}

Table 2: Vector datasets.

\begin{tabular}{|c|c|c|c|c|}
\hline Type of Data & Time period & Source & Projection & Purpose \\
\hline $\begin{array}{l}\text { Base map of } \\
\text { Rwanda and DEM } \\
\text { (Slope generation) }\end{array}$ & 2008 & RNRA & GCS_ITRF_2005 & $\begin{array}{l}\text { Delineating study area extent } \\
\text { and factor maps generation }\end{array}$ \\
\hline $\begin{array}{l}\text { Land use of Kigali } \\
\text { city }\end{array}$ & 2009 & Kigali city & GCS_ITRF_2005 & $\begin{array}{l}\text { Delineating study area extent } \\
\text { and factor maps generation }\end{array}$ \\
\hline $\begin{array}{l}\text { Road network } \\
\text { Paved and unpaved } \\
\text { roads }\end{array}$ & 2008 & ITC & GCS_Arc_1960 & Driving factors of urban growth \\
\hline Main markets & 2008 & CGIS-Butare & GCS_Arc_1960 & $\begin{array}{l}\text { Used as driving factors of urban } \\
\text { growth }\end{array}$ \\
\hline $\begin{array}{l}\text { Land use: DEM } \\
\text { Public } \quad \text { services: } \\
\text { Schools, Hospitals, } \\
\text { post offices.... }\end{array}$ & 2005 & ITC & GCS_Arc_1960 & $\begin{array}{l}\text { Reference for preparing land } \\
\text { cover categories Public services } \\
\text { were used as driving factors of } \\
\text { urban growth }\end{array}$ \\
\hline $\begin{array}{l}\text { Economic areas: } \\
\mathrm{CBD} \text {, industrial area }\end{array}$ & 2008 & RNRA & GCS_ITRF_2005 & $\begin{array}{l}\text { Used as driving factors of urban } \\
\text { growth }\end{array}$ \\
\hline Soil types & & RNRA & GCS_ITRF_2005 & $\begin{array}{l}\text { Used as driving factors of urban } \\
\text { growth }\end{array}$ \\
\hline Wetlands updated & 2014 & Kigali city & GCS_ITRF_2005 & $\begin{array}{l}\text { Used as driving factors of urban } \\
\text { growth }\end{array}$ \\
\hline Zoning plan 2025 & 2013 & Kigali city & GCS_ITRF_2005 & $\begin{array}{l}\text { Proposed zoning to be compared } \\
\text { with the simulated model }\end{array}$ \\
\hline Zoning plan 2040 & 2013 & Kigali city & GCS_ITRF_2005 & $\begin{array}{l}\text { Proposed zoning to be compared } \\
\text { with the simulated model }\end{array}$ \\
\hline
\end{tabular}




\section{Data processing and analysis}

\subsection{Generating land cover maps}

In classifying Landsat images for 1987, 1999, 2009 and 2014, five classes that were considered are builtup, forest, bare soil, and vegetation as well as water bodies. To extract these five classes, more subcategories were defined and merged into main five thematic categories. Built-up included pixels classified as roads and other infrastructures like airport, stadiums as well as other sport grounds. Vegetation included grassland, and green vegetation. The remaining classes were not merged. Water samples were collected both from Kibagabaga artificial pond inside the hinterland and at Muhazi Lake in the Northern part of the city. In applying Maximum Likelihood algorithm, attention should be paid to the separability of samples. This concern was checked using the plot of ellipses of the training samples in the feature space. One of the main difficulties during classification was the confusion between built-up and forest in the Eastern part of the CBD, an area with low density having a mix between built-up and trees. As these two elements have similar responses, their distinction was a heavy task. Hence, several training samples were taken and fuzzy classification was applied.

The study also assessed the accuracy of the 1987-2014 classification. A total of 163 (72 for built-up, 63 for vegetation, 15 for forest, 10 for bare soil and 3 for water) truth ground data were taken and their land cover types were defined from field visual interpretation using Very High Resolution image printed map. High amount of points was collected where there is a high concentration of built-up area. It has to reveal that truth ground data do not precisely go in hand with the classified sample as the VHR image used during field work was for the date of September 2014, while the Landsat image was taken in January 2014. This mismatching may lead to the errors during accuracy assessment, as the same point may have different land cover types between those two dates. However, as the period between two dates is not significant in term of land cover change, this may not disfigure the results. For the results validation, an error matrix of each time span was computed.

The purpose of the study was to look at built-up land cover only whereby land cover maps built-up area were extracted and visualized. A number of built-up pixels in each time span were quantified and the built-up area of each year was derived. To determine the pattern of the city, Patch metrics by Mean Shape Index was calculated. The Mean Shape Index gives information on the pattern (compactness and sprawl) of urban area. The MSI equal to 1 shows the maximally city's compactness and increases as the patch shape become more irregular (scattered). The MSI was calculated for 4 times spans for the study and results reveal different situations. Figure 2 summarizes all steps passed through to generate a consistent set of land cover maps. 
Figure 2: Urban growth mapping and change detection.

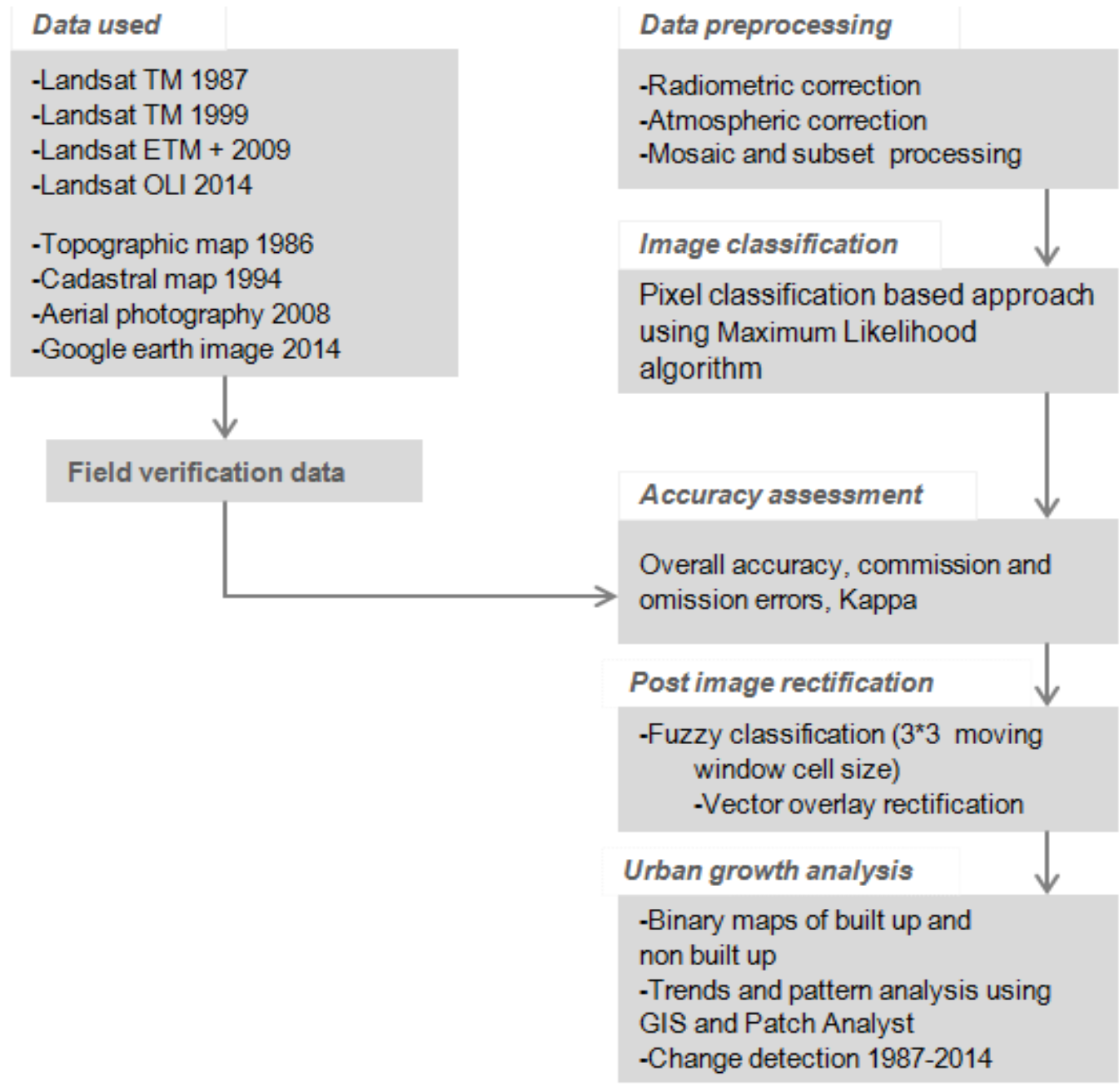

3.2. Logistic Regression Modelling to identify main driving forces of urban growth

Figure 3 highlights the steps passed through to come up with the meaningful drivers of Kigali City growth. Four dummy land cover maps in the periods of 1987, 1999, 2009 and 2014 were used and were defined as 1 for built-up and 0 for non built-up. Then built-up was defined as the combination of vegetation, forest, and bare land cover types. LR Model may be binary or multinomial (Field, 2013). Binary LR Model is used to predict membership of only two categorical outcomes, and Multinomial logistic regression when you want to predict membership of more than two categories used in the model (Field, 2013; Hu and Lo, 2007; Huang et al., 2009). Binary LR Model is a type of regression analysis where the 
outcome variable is a dummy variable (coded 0,1$)$ means Yes or No or built-up and non-built in the context of the present study (Field, 2013; Nong and Du, 2011). The general form of LR Model is showed by the below equation (Cheng, 2003; Field, 2013; Hu and Lo, 2007; Huang et al., 2009; J.Padmavathi, 2012; Rogerson, 2015):

$P(Y)=\frac{1}{1+e^{-\left(b_{0}+b_{1} x_{1 i}+b_{2} x_{1 i}+\cdots+b_{n} x_{n}\right)}}$

where $P(Y)$ is the probability of $Y$ occurring, $e$ is the base of natural logarithms, $b_{0}$ represents the overall occurrence (the overall incidence of built-up in this study); the variable $b_{1}$ represents the fraction by which the likelihood is altered by a unit change in $x_{1} ; b_{2}$ is the fraction by which the likelihood is altered by a unit change in $x_{2} \ldots$ and so on. The estimated probability values lie between 0 and 1 where a value close to $O$ means that $Y$ is very unlikely to have occurred, the value close to 1 means that $Y$ is very likely to have occurred. As the $y$ value increases, the probability $\mathrm{P}$ increases as well.

The factors for the periods 1999-2014, 1999-2009 and 2009-2014 were built. However, the analysis of 1987 with other time spans was not performed due to the data unavailability. These factor maps are independent variables which are either dichotomous or continuous while the dependent one was dichotomous. 
Figure 3: Flowchart showing procedures followed in LR M.

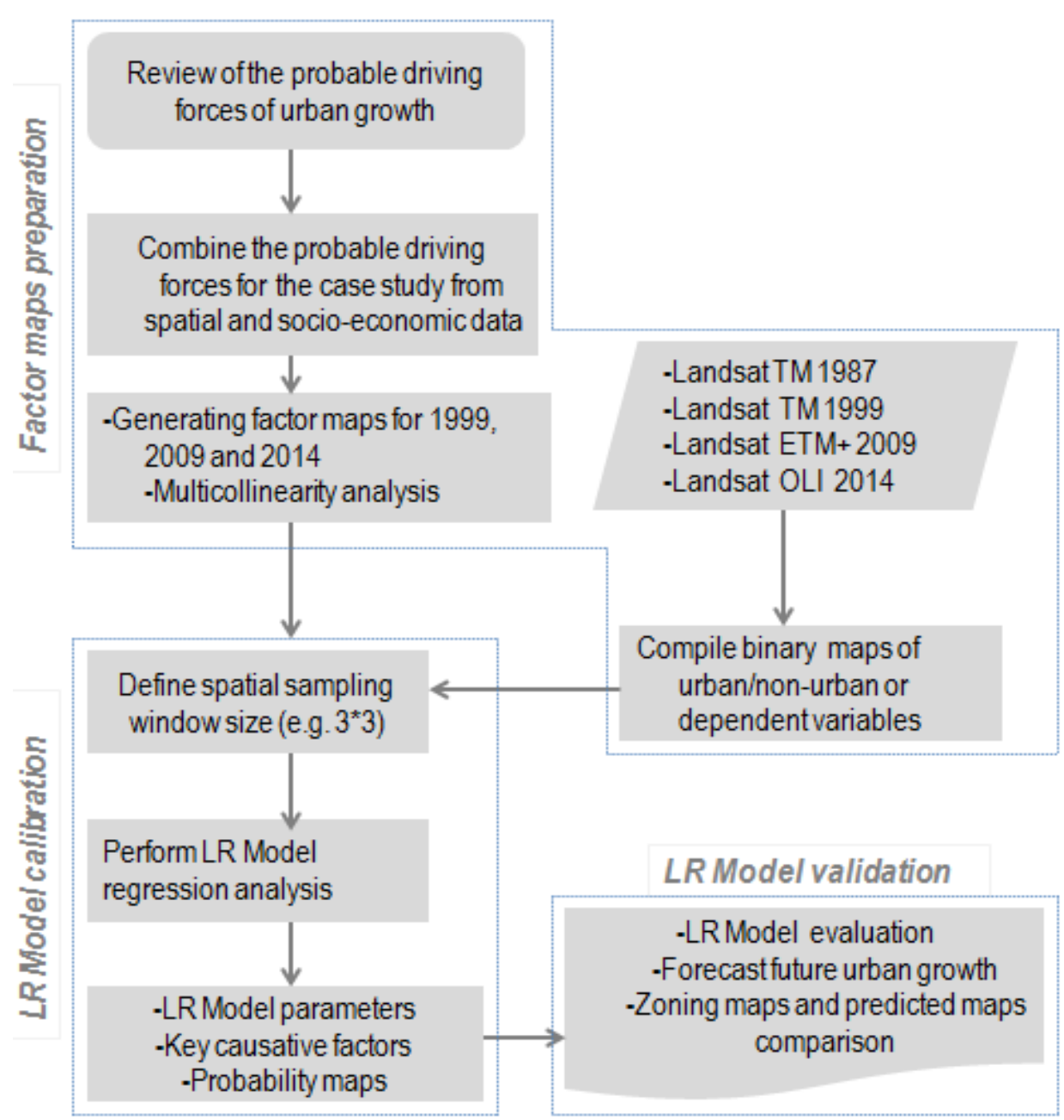

On the basis of factors listed from literature (Cheng, 2003; Dubovyk et al., 2011; Hu and Lo, 2007; Hu, 2004; Huang et al., 2009) and refer to section 2.3, independent variables were prepared for the LRM. Table 3 and Figures 4, and 5 show the factors prepared to be used. All input variables had the same spatial extent (raster size row= 1092 and column=1116), same projection (Transverse Mercator), coordinate system (WGS_1984_UTM_Zone_36N) and same cell

size (30*30 meters). According to Verburg et al. (2004) several factors that influencing the growth of an urban area were subdivided into four different broad categories. These are biophysical constraints and potentials, spatial policies and interaction characteristics factors.

The factor slope was selected under delimited data and used to check whether height had an influence on the development pattern of the city. Forest and wetland were selected with the assumption that wetlands had a connotation of being easily flooded and therefore they might not be developed for urban growth. Moreover, it was selected to check the environmental sensitiveness of Kigali city development. 
Furthermore, commercial and industrial dummy variables were selected as potentials for urban growth. In spatial interaction and neighboring perspective, each development affects the conditions of the neighboring and distant locations (Verburg et al., 2004). Continuous factor maps were prepared representing the proportion of built-up in the year of 1999 and 2009. Here the assumption is that land cover only changes from non built-up to built-up where the inverse is rare in fast developing cities. The Central Business District (CBD) such as main roads and subcentres were considered due to the fact that these CBD and sub centres have an influence on the urban growth, since it is assumed that the land is devoted to the use that generates the most returns; hence most commercial and industrial activities are developed along the development of the CBD. It is therefore assumed, unless proven otherwise, that the CBD has a great positive influence on the urban development pattern since most development will like to be closer to areas with employment opportunities and other social infrastructures. In this case, the road network of 2009 was considered and assumed that most developmental activities will like to be closer to major roads; therefore the road infrastructure has an influence on the development pattern.

As suggested by (Cheng, 2003; Dubovyk et al., 2011; Hu and Lo, 2007; Hu, 2004; Huang et al., 2009; Munshi et al., 2014), it is very important to test the correlation between independent variables to be included in the LRM. Multicollineality is a statistical analysis for the correlation detection among independent variables. When independent variables are correlated among themselves, multicollineality is said to exist (Cheng, 2003). There are some key problems that typically arise when these variables are highly correlated among themselves. Adding or deleting an explanatory variable changes significantly the regression coefficient and the estimated standard deviations of the regression coefficients become larger (Field, 2013; Moore. et al., 2009). Furthermore, it makes some variables statistically insignificant while they are significant. A test of multicollinearity was performed for all independent variables and the Variance Inflation Factor VIF was calculated. VIF is a measure of how much variance of the estimated regression coefficient increases if the explanatory variables are correlated.

$V I F j=\frac{1}{1-R_{j}^{2}}, j=1,2, \cdots k$

where $R^{2} j$ is the coefficient of determination of the regression of the $j^{\text {th }}$ independent variable on the remaining $k-1$ independent variables. The higher the value of VIF the greater is the degree of collinearity. Some authors suggest that if the VIF is less than 10 there is strong evidence that collinearity is affecting the regression coefficients and consequently there are poorly estimated. During analysis, the variables with the VIF higher than 10 were removed from the model.

The test results showed that distance to bus routes, distance to bus stops and distance to commercial areas presented multicollinearity problems since their VIF was above 10 (Table 4). Distance to bus routes was 
eliminated due to the fact that, in Kigali city, all bus routes are also main roads. Distance to bus stop and distance to commercial areas were eliminated in the latter step; this is because in each sub center there are commercial activities.

However, another test performed for the remaining variables showed that there was no multicollinearity since the VIF was below 10 and therefore they were included in the analysis (Field, 2013; Moore. et al.,2009).

Table 3: Explanatory variables that were included in LRM.

\begin{tabular}{|c|c|c|c|c|c|}
\hline Type of variable & Description & $\begin{array}{l}\text { Nature of } \\
\text { variable }\end{array}$ & 1999 & 2009 & 2014 \\
\hline \multicolumn{6}{|l|}{ Dependent } \\
\hline & 1- Built-up 0-non built-up & Dichotomous & - & - & $\bullet$ \\
\hline \multicolumn{6}{|l|}{ Independent } \\
\hline $\begin{array}{l}\text { Bio-physical } \\
\text { influence }\end{array}$ & Slope in percentage & Continuous & $\bullet$ & $=$ & $=$ \\
\hline \multirow[t]{2}{*}{ Land use zoning } & 1- Forest; 0-none forest & Dichotomous & $=$ & $=$ & $=$ \\
\hline & 1- Wetland; 0-none wetland & Dichotomous & $=$ & $=$ & $=$ \\
\hline \multirow[t]{2}{*}{$\begin{array}{l}\text { Neighbourhood } \\
\text { characteristics }\end{array}$} & $\begin{array}{l}\text { Population density } \\
\left(\text { person } / \mathrm{km}^{2}\right)\end{array}$ & Continuous & - & • & - \\
\hline & $\begin{array}{l}\text { Proportion of built-up land in } \\
\text { the surrounding area }\end{array}$ & Continuous & $\bullet$ & $\bullet$ & $\bullet$ \\
\hline \multirow{8}{*}{$\begin{array}{l}\text { Proximity } \\
\text { characteristics }\end{array}$} & Distance to major roads & Continuous & $=$ & $=$ & $=$ \\
\hline & Distance to commercial areas & Continuous & $=$ & $=$ & $=$ \\
\hline & Distance to industrial sites & Continuous & $=$ & $=$ & $=$ \\
\hline & Distance to CBD & Continuous & $=$ & $=$ & $=$ \\
\hline & Distance to sub-centres & Continuous & $=$ & $=$ & $=$ \\
\hline & Distance to health centres & Continuous & $\bullet$ & $\bullet$ & $\bullet$ \\
\hline & Distance to bus routes & Continuous & $=$ & $=$ & $=$ \\
\hline & Distance to bus stops & Continuous & $=$ & $=$ & $=$ \\
\hline
\end{tabular}

- Assumed to be different for each year

$=$ assumed to have the same value in each time span 
Figure 4: 1999 factor maps.
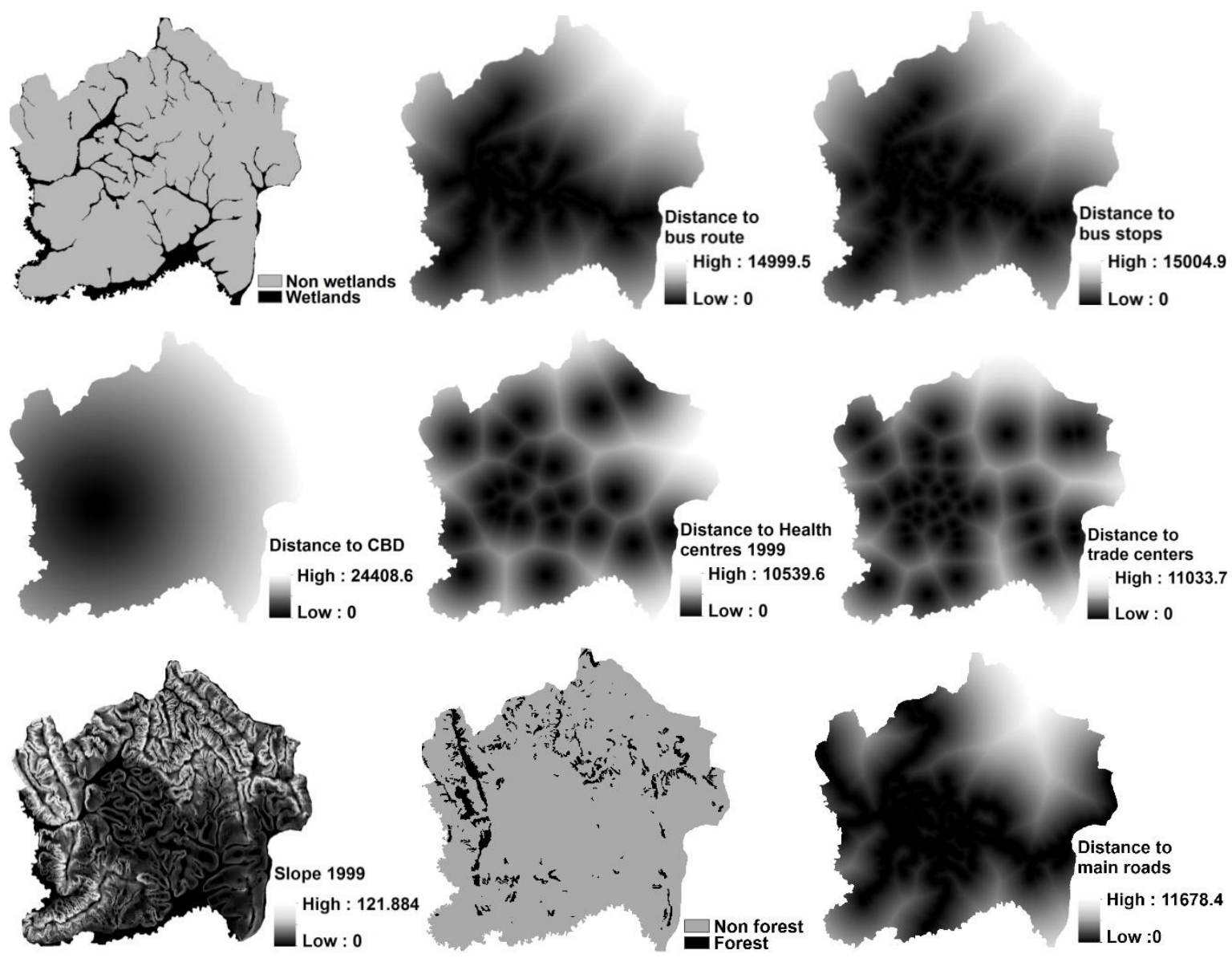

Figure 5: 2009 and 2014 factor maps.
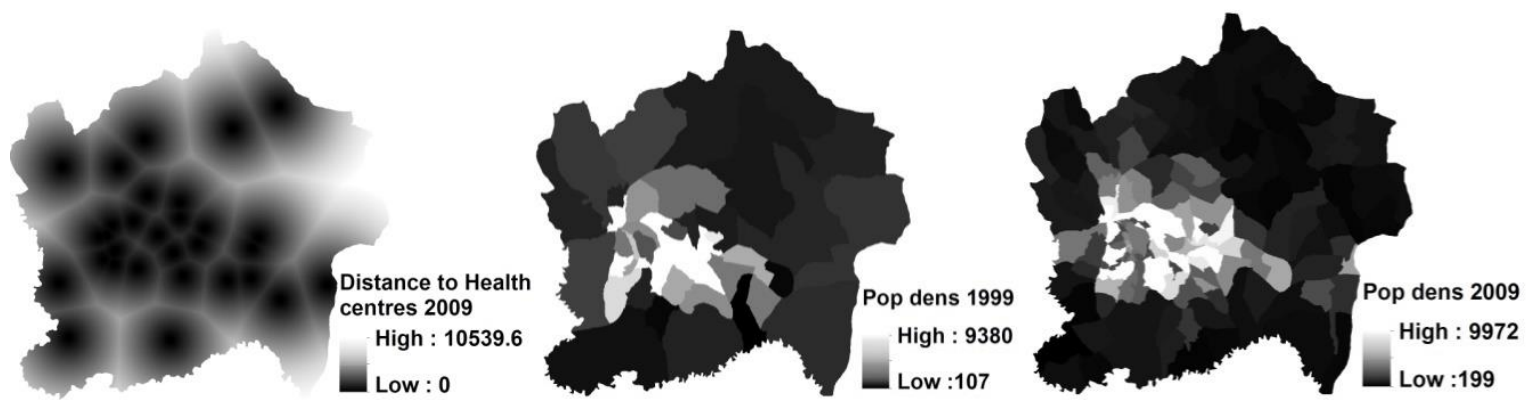

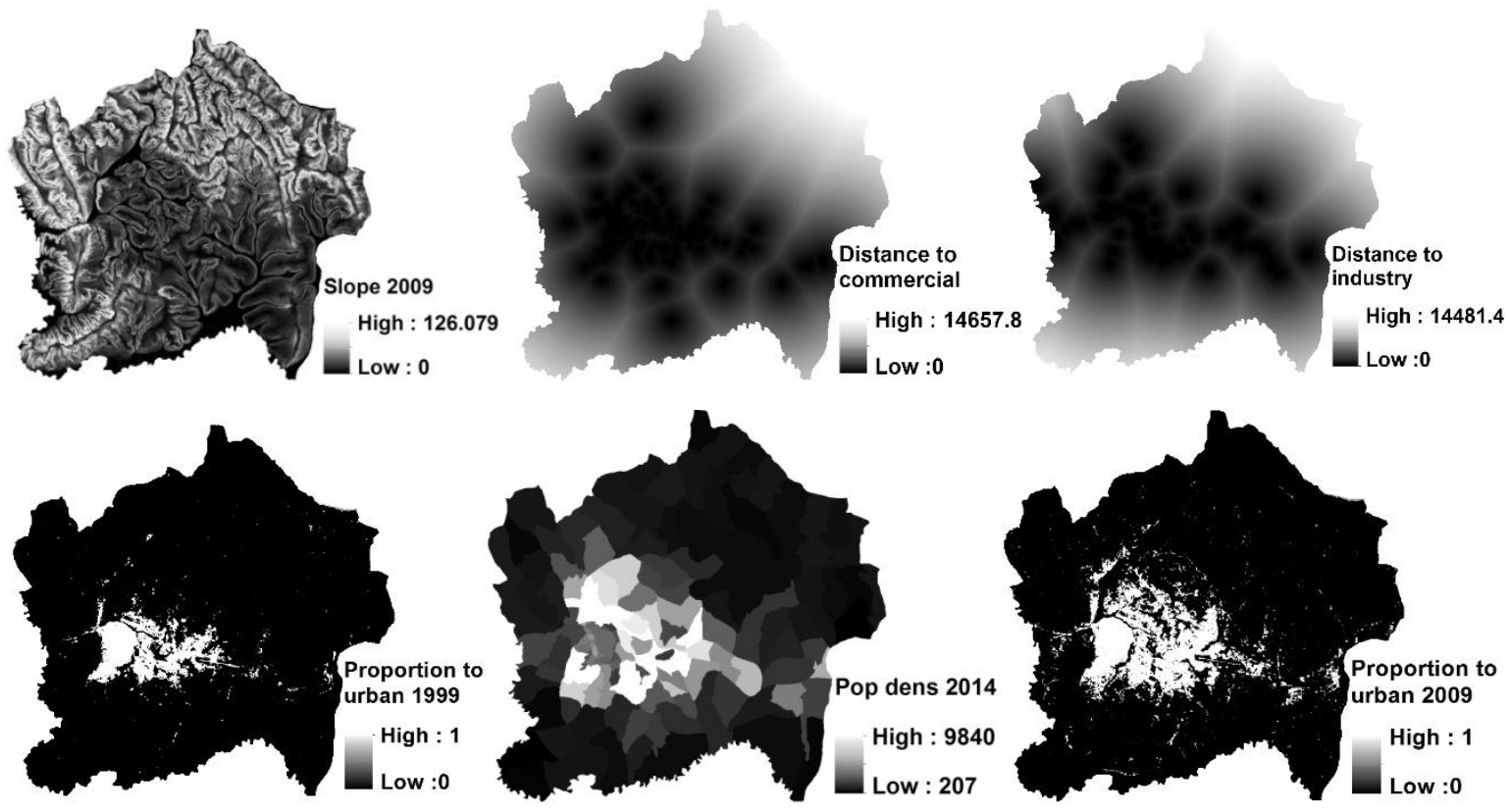

Table 4: Multicollinearity check after eliminating bus routes, bus stops and commercial areas.

\begin{tabular}{clccc}
\hline & Description & VIF 1999-2014 & VIF 1999-2009 & VIF 2009-2014 \\
$X_{1}$ & Distance to bus routes & Eliminated & Eliminated & Eliminated \\
$X_{2}$ & Distance to bus stops & Eliminated & Eliminated & Eliminated \\
$\mathrm{X}_{3}$ & Distance to CBD & 3.126 & 3.472 & 3.384 \\
$X_{4}$ & Distance commercial & Eliminated & Eliminated & Eliminated \\
& areas & & & \\
$\mathrm{X}_{5}$ & Distance to health centres & 2.839 & 3.092 & 3.039 \\
$\mathrm{X}_{6}$ & Distance to industry & 4.000 & 4.350 & 5.079 \\
$\mathrm{X}_{7}$ & Distance to main roads & 2.946 & 3.693 & 3.677 \\
$\mathrm{X}_{8}$ & Distance to trade centres & 2.388 & 2.797 & 2.704 \\
$\mathrm{X}_{9}$ & Proportion of urban in a & 1.576 & 1.726 & 1.820 \\
& surrounding area & & & \\
$\mathrm{X}_{10}$ & Population density & 1.666 & 2.093 & 2.024 \\
$\mathrm{X}_{11}$ & Forests & 1.244 & 1.245 & 1.262 \\
$\mathrm{X}_{12}$ & Wetlands & 1.219 & 1.220 & 1.280 \\
$\mathrm{X}_{13}$ & Slope & 1.542 & 1.505 & 1.589 \\
\hline
\end{tabular}

Using different sampling window sizes, some statistical tests (Backward stepwise procedure, T-Waldtest) were performed to determine the significant drivers to be used and the best LRM 
was chosen. The results of the LRM were interpreted and the future prediction was carried out.

To characterize the future pattern of the city, three scenarios were performed, i.e. urban growth model for expansion (normal growth) and two densification (zoning implication) scenarios. The urban growth model for expansion was performed for the 1999-2014, 1999-2009 and 2009-2014 time spans. However, an urban growth model for densification was computed using the best LRM expansion scenario selection chosen by mean statistical tests. Using the independent variables retained after multicollinearity analysis, 1999-2014, 1999-2009 LRMs and 2009-2014 expansion scenarios were built. On the first stage, all models were created using the 10 retained variables after multicollinerality check as per Table 4 . Using Change Analyst, samples generated from LRM run were used to apply backward stepwise approach in SPSS and factors that had a sound influence on the model were detected (Table 8, 9 and Table 10). The non-significant ones were eliminated from the model as per Table 4. Factors retained after backward stepwise procedure were used to perform LRM regression (Table 8, 9 and Table 10). LRMs were built using different sample sizes varying from $3^{*} 3$ up to $7 * 7$. Finally, to choose the window cell size for modeling, the number of significant factors, and model PCP were looked at (see Table 5). A $3 * 3$ window size was selected for 1999-2014 LRMs and 2009-2014 expansion scenario and $5 * 5$ window size was selected for 1999-2009 model. LRMs expansion scenario regression and probability maps for the three selected expansion scenario models were evaluated by means of Kappa statistic, ROC value and the percentage of 2014 built-up land cover predicted. This was done by comparing built-up of the current urban growth (reference image) and urban development predicted to the current situation (Hu and Lo, 2007; Huang et al., 2009). The assumption is that the present trend's rate and pattern will continue in the future. The best model was retained for densification model simulation and non-selected models were excluded.

Table 5: Statistical tests of LRMs expansion scenario on different sampling window size.

\begin{tabular}{llll|lll|lll}
\hline Criteria & \multicolumn{3}{c|}{$1999-2014$} & \multicolumn{3}{|c|}{$1999-2009$} & \multicolumn{3}{|c}{$2009-2014$} \\
Window size & $3 * 3$ & $5 * 5$ & $7 * 7$ & $3 * 3$ & $5 * 5$ & $7 * 7$ & $3 * 3$ & $5 * 5$ & $7 * 7$ \\
Significant drivers forces & 5 & 4 & 5 & 6 & 5 & 5 & 7 & 6 & 4 \\
PCP (built-up) & 94.94 & 94.88 & 94.67 & 94.13 & 94.23 & 94.11 & 95.78 & 95.74 & 95.73 \\
\hline
\end{tabular}

In LRMs for densification scenario, the proposed zoning for 2025 and 2040 were considered (Edaw et al., 2007; Surbana, 2012). Factors maps for the 
2025 to 2040 zoning plan indicating land allowed to be developed or not were prepared. The idea of using both expansion (normal growth or business as usual) and densification (zoning enforced) scenarios was because the city will continue to encourage people to build in the proposed zoning in the future. The zoning scenario implies that illegal constructions will be controlled in the future and proposed zonings will be respected. The 2025 and 2040 zoning factor maps were used to predict both 2025 period and 2040 situation respectively.

The idea behind the densification scenario was that new urban developments will tend to occur in the proposed zoned areas. Under this scenario, two sub- scenarios were simulated (strict zoning policy and moderate zoning policy). For each policy sub-scenario, the start and end year date dependent factor maps were prepared (1999 as initial year and 2014 as end year). Using ArcGIS from raster calculator, 1999 land cover was combined with 2025 and 2040 zoning binary map, 2014 land cover with 2025 and 2040 respectively. Four attributes were generated as zoned-currently built area, zoned but not currently built, not zoned currently built and not zoned currently not built. For the strict zoning sub-scenario, factor maps dichotomous dependent variables were prepared and given as 1 zoned-currently built area and 0 zonedbut not built (see Figure 6). However, not zoned-not built and not zoned but currently built were treated as no data. This implies that these areas are not assigned (not suitable) for future development. The assumption taken here is that the future city pattern will depend only on area allowed for allocation according to zoning policy. For moderate zoning, the same process was repeated but not zoned but currently built-up areas was combined with zoned- currently built and were given 1 as value. The idea behind the moderate zoning policy was to predict the future pattern of the city when existing built-up areas outside the zoning will not be demolished. The said areas to be demolished according to zoning policy includes formal residential and industrial area which are closed to wetlands, informal settlements close to protected forest mostly located in the Western and Southern part of the city on Mont Kigali and Mont Jali. The city planned afforestation and recreational activities in those places. 
Figure 6: Densification factor maps.

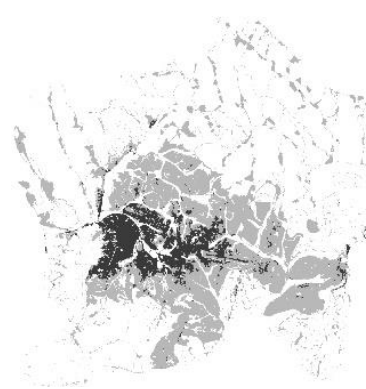

STR_1999-2025

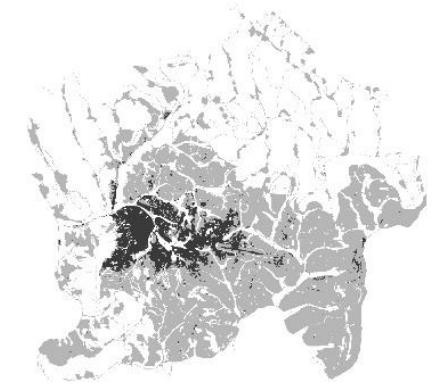

STR_1999-2040

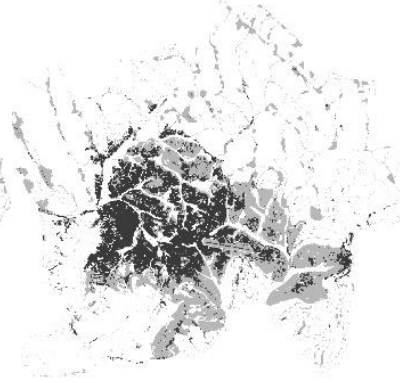

STR_2014-2025

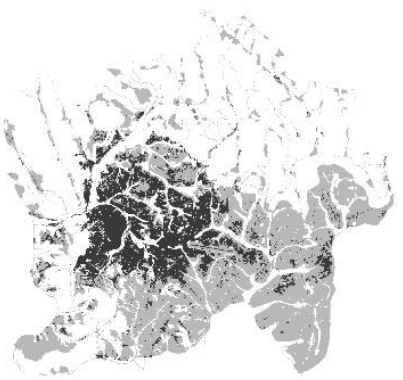

STR_2014-2040
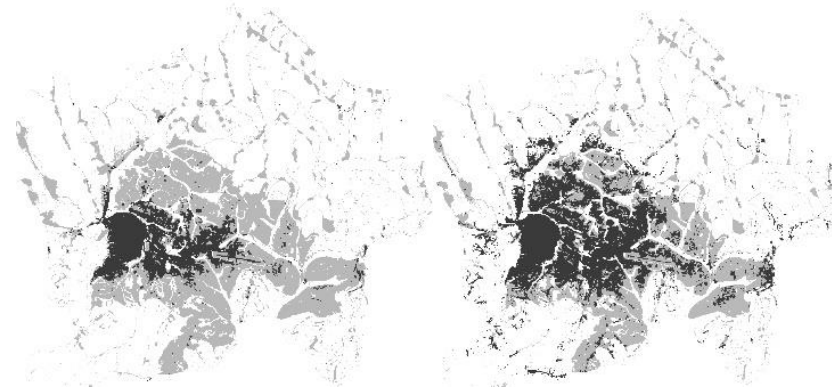

MDR_1999-2025

MDR_2014-2025

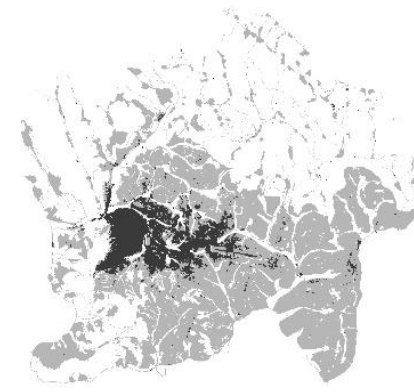

MDR_1999-2040

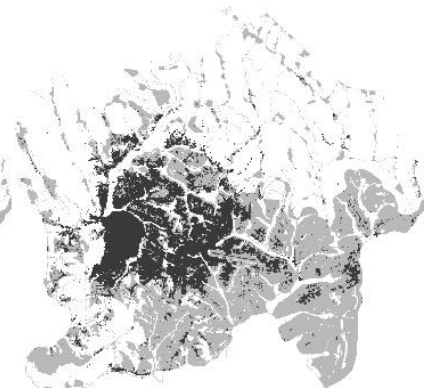

MDR_2014-2040

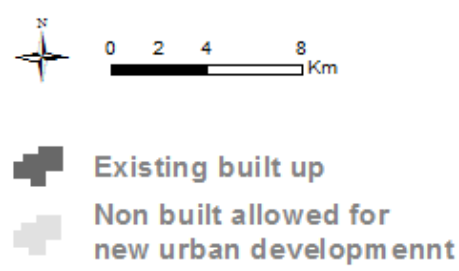

STR: Densification with strict zoning policy MDR: Densification with moderate zoning policy 


\section{Results}

4.1. Urban growth trends and pattern of Kigali city

Figure 8 shows that the amount of urban growth and its increment during 1987-2014, built-up area has increased considerably. It doubled from 1987-1999 and 1999-2009 while there has been a gradual change between 2009 and 2014. The average annual growth rate from 1987 to 2014 was

almost $10.24 \%$. The overall accuracy was $84.23 \%$ for 1987 classified image, $86.51 \%$ in $1999,88.34 \%$ for 2009 and $93.87 \%$ in 2014 (Table 6).

Figure 7: Spatial pattern of urban growth between 1987-2014.

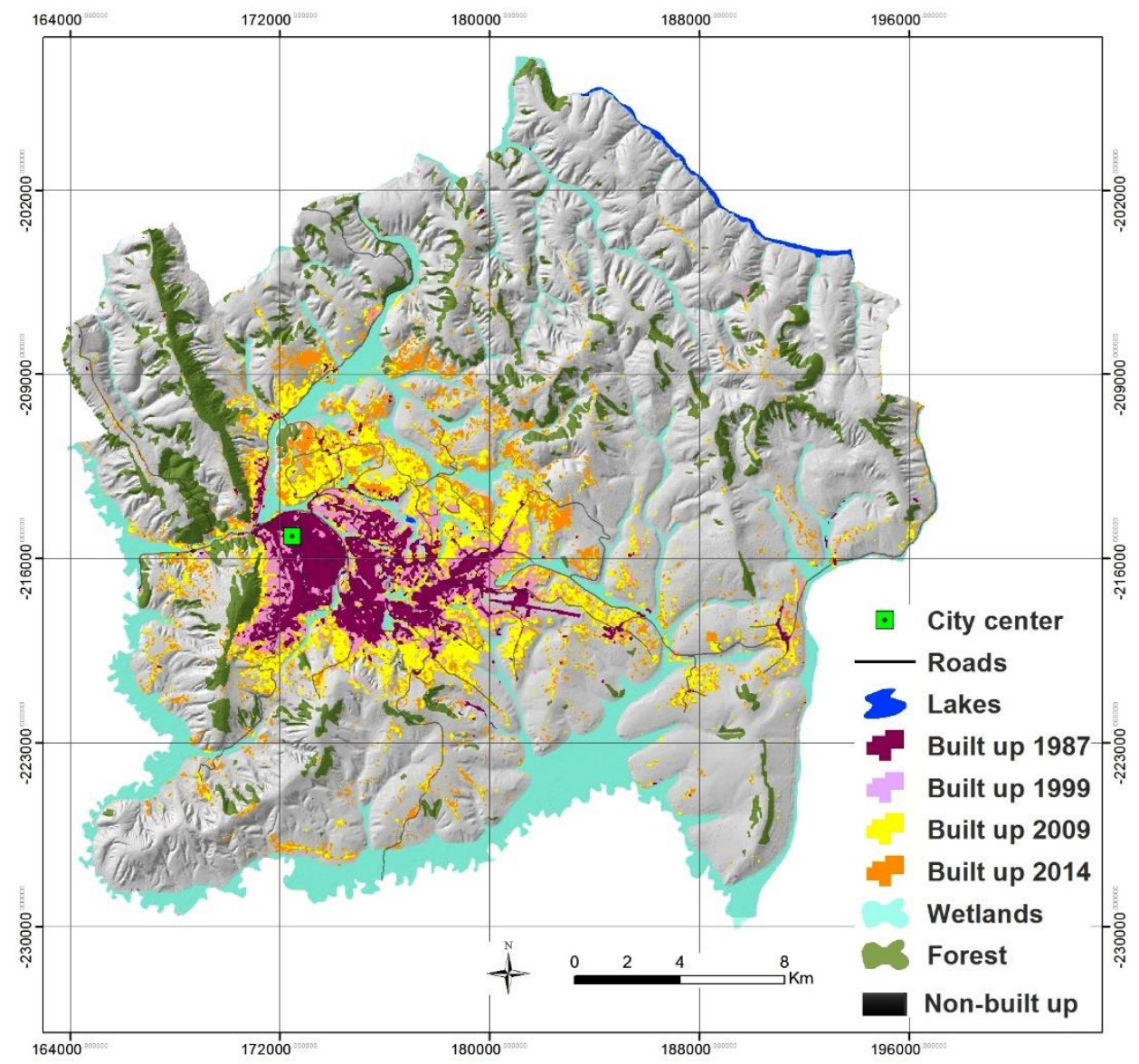

Figure 8: The built-up land cover trends in Kigali City. 


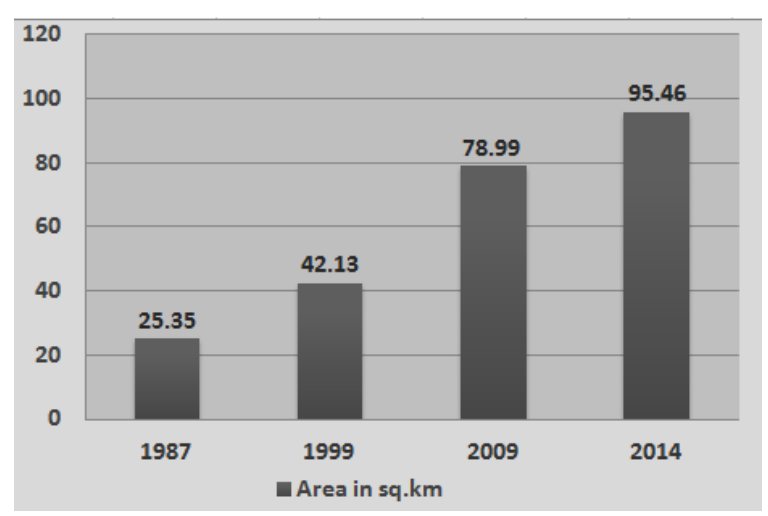

The overall accuracy was $84.23 \%$ for 1987 classified image, $86.51 \%$ in 1999, 88.34\% for 2009 and 93.87 $\%$ in 2014 as per Table 6.

Table 6: Accuracy assessment results.

\begin{tabular}{lccc}
\hline \multicolumn{1}{c}{ Sensor } & Classified image & Overall accuracy & Kappa statistics \\
Landsat TM & 1987 & 84.23 & 0.76 \\
Landsat TM & 1999 & 87.51 & 0.79 \\
Landsat ETM+ & 2009 & 88.34 & 0.81 \\
Landsat OLI & 2014 & 93.87 & 0.89 \\
\hline
\end{tabular}

In In general, the urban growth of Kigali City between 1987 and 1999 was sprawled but some dense areas can be observed per Figure 7. Some more compactness can be seen in the CBD and other existing builtup areas. The city became more sprawled in 1999 in comparison to 1987. In 2009, the urban sprawl decreased in some part of the city and in 2014 there was a bit more compactness in many urban areas. Between 2009 and 2014, there was a remarkable extension trend in all sides of the city except the Western part. However, the tendency is higher to the Northern and Eastern sides while the Western was paused. In the Western direction of Kigali, the topography is critical for built-up since this part was protected by forests cover. Furthermore, some new built-up areas appeared in the hinterland of the Southern part. These are smaller and dispersed built-up patches compared to the Northern and Eastern development. The differences between the years 1987 and 2014 are of large magnitude, it can be said that the expansion pattern of Kigali City is horizontal and densification is very low. Rural lands have been converted into built-up areas due to the increase in urban activities (REMA, 2013). There is a big demand for land by the high number of offices, schools, industries built during last 27 years. Moreover, citizens constructed bungalows instead of high rise apartments. In the process of urbanization, apart from the CBD, new subcentres were created and this multicentre development has been stated in the series of master plans 
elaborated for Kigali City. As showed in Figure 9, the decreasing value of MSI from 1987 to 1999 confirms the tendency of

the city's compactness. However, from 1999 to 2009, the city sprawled to the hinterlands in all directions as the value of MSI increases. From 2009 to 2014, the city was posed. The reason is that recently illegal developments were stopped and the city authority started vertical development campaign (Edaw et al., 2007; Surbana, 2012).

Figure 9: Sprawl and compactness pattern of Kigali city.

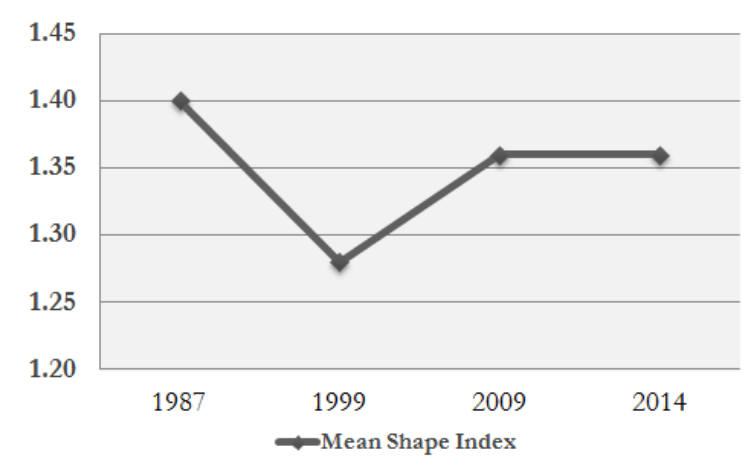

4.2:1999-2014 LRM expansion scenario simulation

The final 1999-2014 LRM was obtained on the sixth backward stepwise procedure after eliminating factors like forest cover, distance to trade centres, distance to industry, distance to main roads, and population density since their T-Wald statistic (p-values) were greater than the assigned confidence interval (greater than 5\% level of significance). The overall model was significant with chi-square of 91654.6792 and corresponding p-value of less than 0.0000 at the $1 \%$ level of significance. The sampling window size for this model was $3 * 3$ since it has a higher number of significant factors and higher $94.94 \%$ of PCP comparing to other moving windows. The summary of the model is presented in Table 8. 
Table 8: Variables in the equation of 1999-2014 LRM expansion scenario.

\begin{tabular}{lccccc}
\hline Variables & $b$ & SE $(b i)$ & z-value & T-Wald test (p-value) & \multicolumn{1}{c}{ O.R } \\
Constant & -0.32880 & & & - & - \\
CBD & -0.00015 & 0.000005 & -31.841 & 0.000 & 0.999853 \\
Health centres & -0.00017 & 0.000016 & -10.636 & 0.000 & 0.999831 \\
Slope & -0.04829 & 0.001799 & -26.837 & 0.000 & 0.952861 \\
Wetlands & -2.41260 & 0.098619 & -24.463 & 0.000 & 0.089582 \\
Proportion of urban & 5.15426 & 0.064000 & 80.535 & 0.000 & 173.168106 \\
\hline
\end{tabular}

\section{3: 1999-2009 LRM expansion scenario simulation}

This final LRM ( $5 * 5$ moving window size selected) was obtained on the sixth backward step after eliminating factors like forest cover, population density, distance to trade centres, distance to industries and distance to main roads. As mentioned in Table 9, five variables were

significant with the p-value less than $5 \%$ level of significance. The overall model was significant with chi-square value of 16986.0256 and p-value of less than 0.0000 at the $1 \%$ level of significance. Different variables of this LRM have different probability degrees of influence on urban growth. The overall accuracy (PCP) was 94.23\%, while Kappa value was 0.63 .

Table 9: Variables in the equation of 1999-2009 LRM expansion scenario.

\begin{tabular}{lccccr}
\hline Variables & \multicolumn{1}{c}{$b$} & SE $(b i)$ & z-value & T-Wald test (p-value) & \multicolumn{1}{c}{ O.R } \\
Constant & 1.63140 & & & - & - \\
CBD & -0.00024 & 0.000008 & -29.637 & 0.000 & 0.999753 \\
Health centres & -0.00057 & 0.000030 & -19.100 & 0.000 & 0.999428 \\
Proportion of urban & 6.66083 & 0.362504 & 18.374 & 0.000 & 781.203768 \\
Wetlands & -2.50502 & 0.151870 & -16.494 & 0.000 & 0.081673 \\
Slope & -0.05047 & 0.002554 & -19.759 & 0.000 & 0.950780 \\
\hline
\end{tabular}


4.4: 2009-2014 LRM expansion scenario simulation

Among 10 variables included in the model, variables like distance to roads, forest and slope were eliminated after performing backward stepwise procedure. The model was found at the fourth step after eliminating factors like distance to roads, forest cover and slope. The sampling window of $3 * 3$ was selected as it contains a higher number of drivers compared to other window sizes. This overall model was significant with chi-square of 88889.8764 and corresponding p-value of less than 0.0000 at the $1 \%$ level of significance. The PCP was $95.78 \%$, while Kappa value was 0.76. Hence, the model was not included for further analysis. The summary of the model is presented in Table 10.

Table 10: Variables in the equation of 2009-2014 LRM expansion scenario.

\begin{tabular}{lccccc}
\hline Variables & $b$ & SE $(b i)$ & z-value & T-Wald test (p-value) & $O . R$ \\
Constant & 0.427200 & & & - & - \\
CBD & $-6.7 \mathrm{E}-05$ & 0.000006 & -11.705 & 0.000 & 0.999933 \\
Industry & -0.000170 & 0.000012 & -13.841 & 0.000 & 0.999835 \\
Trade centres & -0.000120 & 0.000022 & -5.524 & 0.000 & 0.999980 \\
Population density & 0.000288 & 0.000013 & 6.694 & 0.000 & 1.000088 \\
Health centres & -0.000200 & 0.000020 & -10.027 & 0.000 & 0.999801 \\
Wetlands & -2.083070 & 0.125171 & -16.641 & 0.000 & 0.124548 \\
\hline Proportion of urban & 5.913287 & 0.139958 & 42.250 & 0.000 & 369.505638 \\
\hline
\end{tabular}

All final LRMs expansion scenarios were constructed using 10 variables. All three LRMs were significant at less than $5 \%$ of level of significance. The variable increases the probability of urban growth if it has a positive sign or decreases the probability in case it has a negative sign. For the 1999-2014 model, the proportion of built-up land in the surrounding area has a positive effect on urban growth while distance to health centres, distance to the $\mathrm{CBD}$, slope and wetlands were major determinants with negative effect on the urban growth occurrence; as closer (less distance) the more the likelihood of being built-up. Based on the values of $b$ and O.R (Table 8), it can be seen that the 1999-2014 LRM for expansion' variables had a different degree of influence of probability on urban growth. Normally, a strong positive $b$ value of the predictor indicates a strong positive relation between that predictor and urban growth. A negative large $b$ value explains the strong negative impact of the predictor to the urban growth. Moreover, $b$ can be linked to the values of O.R to explain the model variables influence to the urban growth. The 
proportion of built-up land in the surrounding area contains a coefficient $b$ value of 5.15 and O.R value of 173.16. This implies that an increase of the proportion of built-up land in the surrounding area increases the likelihood or probability of urban growth. All resulting model parameters with an odds ratio greater than 1 and with positive $b$ value can be interpreted in this way.

All remaining variables (CBD and Health centres) have a negative $b$ values and odds ratio less than 1. This implies that the higher distance from the CBD or health centres, the lower is the probability of urban growth and the lower distance from the CBD or health centres the higher is the probability of urban growth. Also, according to the estimated model parameters, slope and wetlands impact negatively urban growth occurrence. This indicates that new urban developments have a tendency to occur away from wetlands and on the low and gentle slope sites. 1999-2009 and 2009-2014 LRMs can be interpreted in the same way as 1999-2014 model. The strong positive relationship between the proportion of urban in a neighborhood area is logical in case of Kigali city. From (Figure 7), it can be seen that the new urban developments were mostly developed in a clustered pattern around the existing urban area. Surprisingly, proximity to the road network which is found as main driving factors in most similar urban development studies Huang et al. (2009); Nong and Du (2011); Verburg, et al. (2004) was not statistically significant in this study. The absence of paved (called main roads in this study) especially in the Northern and Southern part of the city: new developed areas after 1999 (refer to land cover maps Figure 7) might be related to the roads elimination in the model. Normally, urban developments tend to occur in the areas of higher road accessibility, which is common in most developing cities. Refer to Table 8 , it can be concluded that the proportion of urban in a neighborhood area was the most important predictor of urban growth in Kigali city. Distance to the CBD, distance to health centres, slope and wetlands have low probability to influence urban growth. Table 11 presents the most three important factors for 1999-2014, 1999-2009 and 2009-2014 LRMs time spans.

Table 11: The most important factors for 1999-2014, 1999-2009 and 2009-2014 LRMs.

\begin{tabular}{llcl}
\hline Top three factors & 1999-2014 & Time period of LRM & \\
First rank & The proportion of urban & The proportion of urban & The proportion of urban \\
& in a neighborhood area & in a neighborhood area & in a neighborhood area \\
Second rank & Slope & Slope & Population density \\
Third rank & Health centres & Health centres & Health centres \\
\hline \hline
\end{tabular}


4.5: LRMs expansion scenario validation and prediction

To choose the best LRM expansion scenario, PCP, Percentage of correct prediction, Kappa statistic and ROC values and the Percentage of current built-up predicts were calculated.

Statistically and visually, 1999-2014 LRM expansion scenario shows a trend of a certain reality of urban growth over time based on the current situation model. This model predicted $71.01 \%\left(71.92 \mathrm{~km}^{2}\right)$ of the total current built-up with 0.750 ROC value and 0.75 Kappa statistic.

Table 12: Statistical test for LRMs expansion scenario.

\begin{tabular}{l|c|c|c}
\hline Measure & $1999-2014$ & $1999-2009$ & $2009-2014$ \\
Correct prediction & 758761 & 748461 & 756949 \\
PCP & 94.82 & 93.96 & 94.82 \\
Kappa statistic & 0.75 & 0.63 & 0.76 \\
$\%$ of 2014 Land cover Built-up & 75.46 & 72.07 & 77.48 \\
predicted & & & \\
ROC & 0.750 & 0.716 & 0.754 \\
\hline \hline
\end{tabular}

Figure 8: Comparison of interpolated (2014 built-up prediction of 1999-2014 LRM expansion scenario) versus observed (reality) 2014 built-up cover.

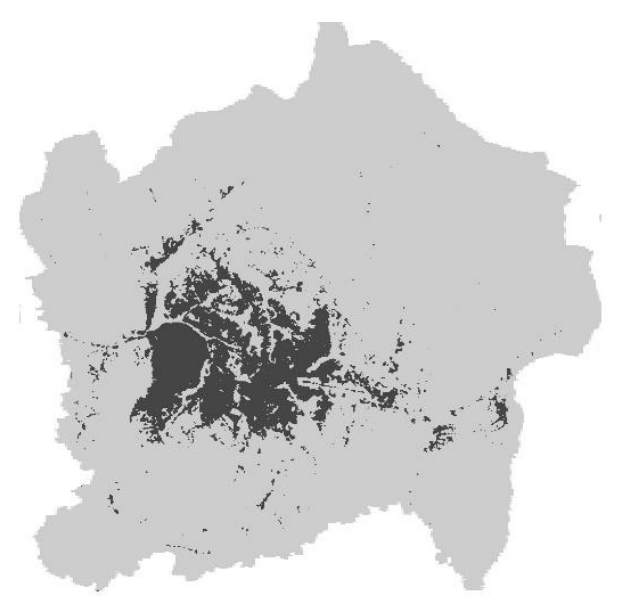

Built up area

Non built up area

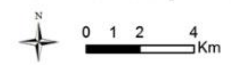

1999-2014 LRM Expansion scenario predicted in 2014 Built-up of actual 2014 urban growth 
Based on the visual and statistical pattern in Table 12 and Figure 8, the validation results let us conclude that 1999-2014 LRM leads to satisfying results in predicting the future pattern of the city. Therefore, the 1999-2014 model was chosen as input for densification model scenarios. It has a satisfactory Kappa and ROC values and a high percentage of correct cells pixels predicted. There is a moderate similarity between the model prediction and the actual situation pattern. However, the resulting prediction pattern is more compact than the actual 2014 land cover map. In addition, the 1999-2014 LRM was chosen with an assumption that it is a long period model; factors (independent and dependent variables) were updated in term of city trend and pattern. Independent variables like health centres (in term of counts) proportion of built-up in the neighboring were updated compared to 1999-2009 model. However, 2009-2014 model was found worse to predict the future pattern of the city. It tends to convert existing built-up into non built-up. It is a short time period compared to the others, there is a slight difference in term of trend and pattern between start and end year periods.

\subsection{LRMs densification scenario and zoning implications}

These scenarios allowed comparison of policy options and decisions since it compare and quantify the built-up areas between densification scenario model for planned areas in 2025 and 2040 (2012 Master Plan of Kigali City) as well as an expansion scenario model of the actually developed urban land predicted in 2025 and 2040. All three models have a nearly equal spatial match. Three scenarios generated have patterns characterized by a strong compactness of urban densities. Expansion scenario is more compact, compared to other scenarios. This is logical since expansion scenario tends to convert a higher amount of forest and wetlands land cover into built-up. However, all three models tend to exclude urban units in the Eastern-Southern part of the city. The area currently characterized by lower urban density and low health care accessibility which might be related to the model pattern found as shown in Figure 9. By comparing patterns between 2025 and 2040 for both densification scenario and zoning maps, it can be seen that LRMs for 2025 and 2040 densification scenario were quite spatially different from the proposed zoning maps. The three models tend to exclude urban units in the Eastern-Southern part of the city since the variables used in the model were not able to capture a pattern in that part of the city. Refer to Figure 7; the Eastern-Southern part of Kigali City is mostly occupied by agricultural land therefore any of the variables can predict built-up in that location. This is because the place is not urbanized; no health centres and is located far from the CBD. Figure 10 shows the trend of the city up to 2040 and indicates that the city trend will be double the current situation if the current trend rate continues to be the same. Figure 9 shows the probability maps of all LRMs densification scenarios that were compared with LRMs expansion. 
Figure 9: Comparison of extrapolated 2025 and 2040 LRMs Expansion and Densification scenario.

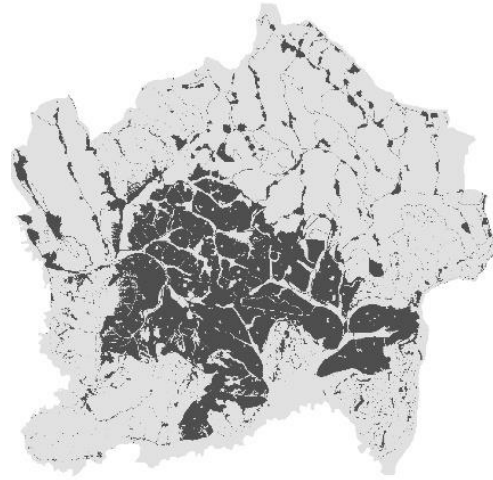

2025 zoning land use map

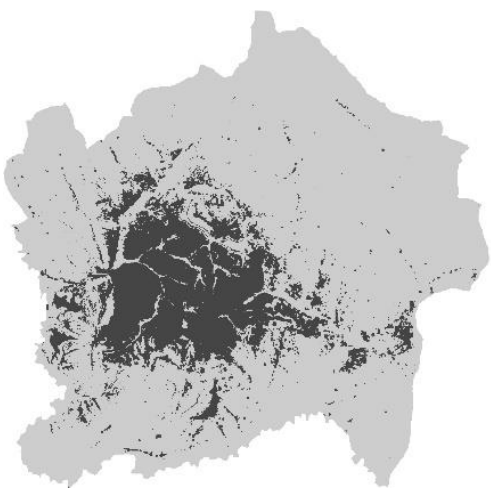

1999-2014_2025 Expansion

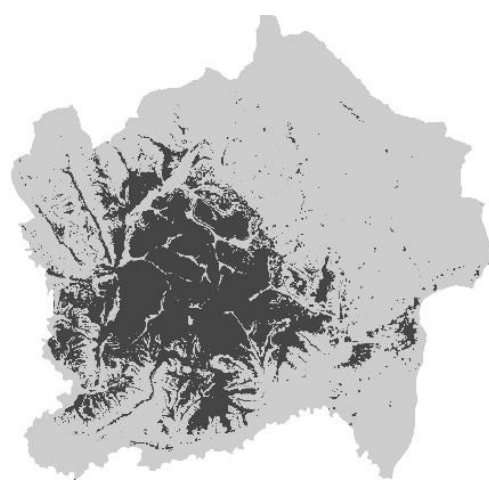

1999-2014_2040 Expansion

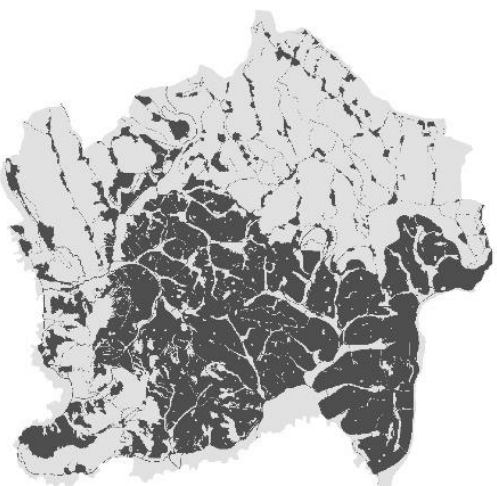

Built up area

Non built up area

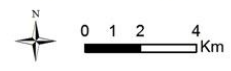

2040 zoning land use map

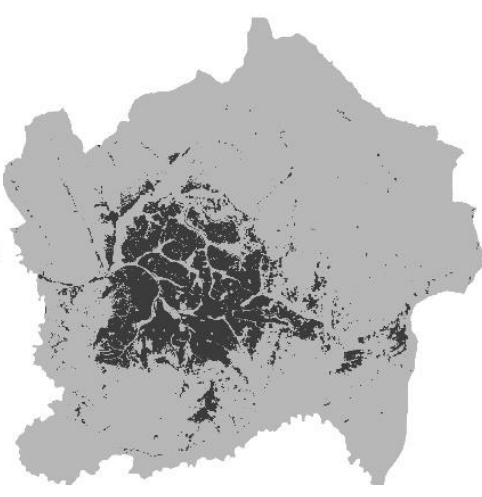

STR_2025 zoning

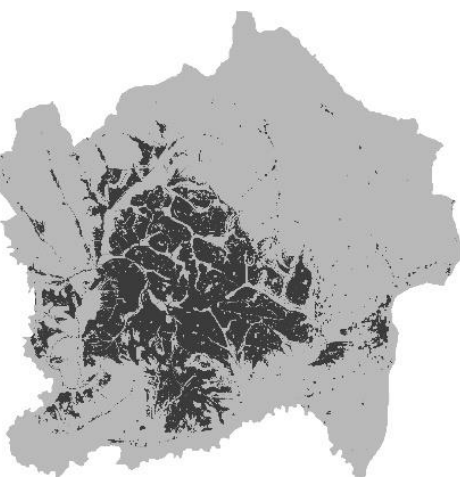

STR_2040 zoning

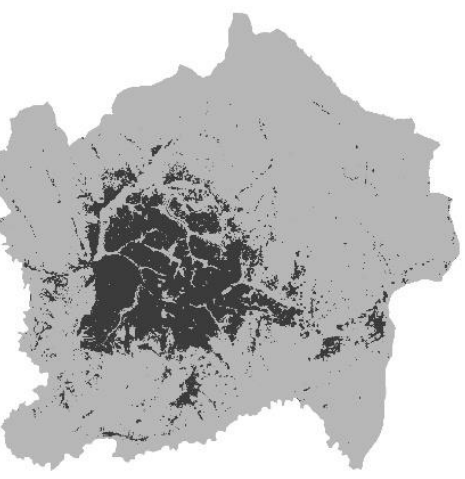

MDR_2025 zoning

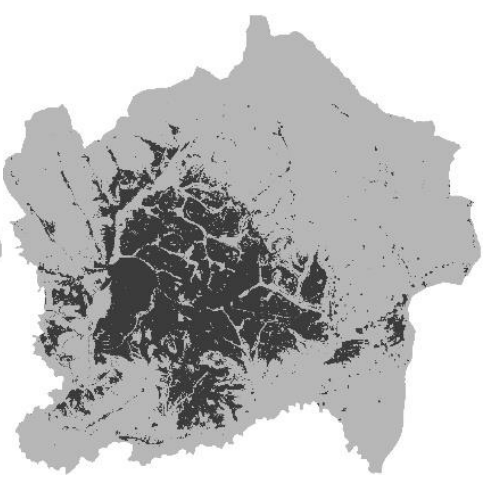

MDR_2040 zoning

STR: Densification with strict zoning policy;

MDR: Densification with moderate zoning policy

Figure 10: Built-up areas of different scenarios. 


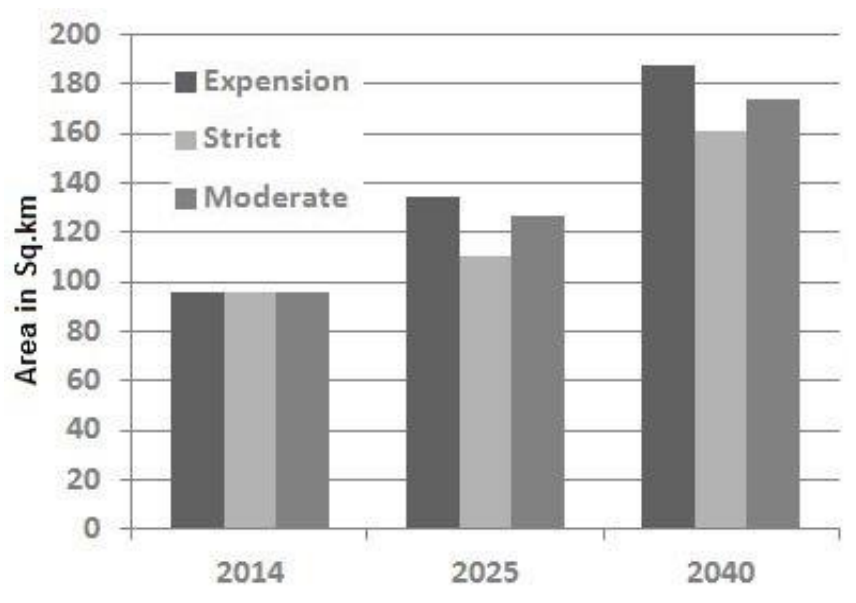

\section{Discussion}

LRM was applied in this study to determine the main driving forces of urban growth and predict future urban growth pattern in the study area in the next 26 years. The results of this study indicated that new urban developments in Kigali City will tend to be close to the existing urban areas, hence a compact pattern. This is logical for Kigali city due to the city experience of a massive horizontal urban growth pattern. This shows how important spatial policies (condominium law and 2012 Kigali City Master Plan) are to deal with horizontal growth and reduce its negative impact of adopting vertical urban growth pattern. It also shows that; new urban development will have a tendency to occur further from the CBD and wetlands but on low slope sites. This proves what have been found by Edaw et al. (2007), slope greater than $20 \%$ were deemed as unsuitable for urban development in Kigali City due to the fact that steep slope sites increase landslides, erosion, problems with road designs, construction and maintenance. Moreover, steep slope sites are less practicable in term of fire protection equipment and emergency vehicles in case of any risk occurrence. However, health centres impact the new urban development in a negative way. This can be linked with the efforts of the Government of Rwanda on improving accessibility on health care facilities within an acceptable distance from the inhabitants (Surbana, 2012).

Drivers of urban growth may change from one case study to another, because of data availability Cheng (2003); resources (Hu, 2004; Huang et al., 2009) and modeling approach (Hu and Lo, 2007; Nong and $\mathrm{Du}, 2011)$. In the similar urban growth cities, factors proportion to urban areas, distance to the CBD and slope were reported as main drivers of urban growth see Table 11. Among factors Hu and Lo (2007) reported, neigbboring to urban area and distance to economic centres came at the first place as main driving forces of urban growth in Atlanta city, Georgia, USA. Moreover, Huang et al (2009) concluded that proportion to urban areas, zoning, and distance to roads were key drivers of New Castle city growth. 
Using the same approach, Dubovyk et al (2011), found that slope and population density impacted the proliferation of informal settlement in Sancaktepe, Instanbul, Turkey.

Empirical results from LRM used three scenarios to simulate the future built-up trends and patterns of the city, namely expansion scenario called normal growth (derived from past and present pattern of builtup area land cover) and densification scenario (simulated from the best 1999-2014 expansion scenario model and policy implication of 2025 and 2040 proposed zoning maps). Both 2025 and 2040 prediction for expansion and densification scenarios model maps were compared with the proposed 2025 and 2040 zoning maps.

The 1999-2014 LRM expansion scenario predicted that if the current physical urban expansion rate continues, urban development will expand towards Northern and Southern direction of the city rather than Western and Eastern parts. The new developments have a tendency to replace forest cover and wetlands in the Western part of the city and this constitutes a serious environmental threat to the city. This 19992014 expansion scenario model selected was validated by means of Kappa statistic and ROC value whereby values of 0.75 for Kappa statistic and 0.750 for ROC showed the robustness of the results, which implies that the model was good to predict the real pattern of the future of Kigali city. In land use/cover change modeling, a kappa value higher than 0.5 can be considered as satisfactory (Lesschen et al., 2005). Kappa and ROC value found in this study can be compared to what have been found by (1) Dubovyk et al. (2011) with a Kappa of 0.50, 0.49, 0.65 with a ROC value of 0.81, 0.82 and 0.94; (2) Nong and Du (2011) with the ROC value of 0.891 . The 0.75 and 0.750 kappa and ROC values found in this study can ensure the validity of the model built to predict the future urban growth of the city.

Three scenarios generated have patterns characterized by a strong compactness of urban densities. Expansion scenario is more compact, compared to other scenarios. This is logical since expansion scenario tends to convert a higher amount of forest and wetlands land cover into built-up while the policy scenarios will protect the land. However, all three models tend to exclude urban units in the EasternSouthern part of the city compared to the proposed zoning maps. The area currently characterized by lower urban density and low health care accessibility which might be related to the model pattern found. In modeling perspective, the method chosen should fit the research questions, data availability, time and resources (Lesschen et al., 2005). This study was subjected to the data constraints which is a serious problem in urban growth modeling in developing cities (Hu and Lo, 2007). The model relies on very limited factors therefore its outcomes should be looked at model inputs. All factors given by respondents to be considered as drivers of urban growth were not included in the model due to the data unavailability and their integration capability in LRM for extracting meaningful information. Variables such as neighboring characteristics (regular water and electricity provision) were not incorporated in the model 
whereby their presence might have improved the model performance. In addition, compilation of data used suffers from processing anomalies of spatial and temporal resolution inconsistency. In this case, Landsat TM classified specifically for 1987 and 1999 lacked temporal consistent validation data (1986 topographic map used for 1987 and 1994 cadastral map used for 1999). Population densities were extrapolated and interpolated. Again, Landsat data $(30 * 30$ meters cell size resolution) lacked the capability to capture patterns on a micro level scale of change. However, using high resolution Remote Sensing data (1 meter resolution of IKONOS, 0.64 meters resolution of Quickbird) may remove classification anomalies (salt and pepper pixels of built-up and bare land), which could improve the pattern comparison and model performance.

The spatial analysis for this study was based on the $30 * 30$ meters pixel size as the spatial resolution of Landsat images used in this research. Therefore, other variables used were resampled and conformed to this resolution for the model sensitivity. However, other resolutions from $10 * 10$ meters to $20 * 20$ meters need to be comparatively checked for the robustness analysis of this LRM study results in the future studies. LRM (Change Analyst) lacks the capability to analyze the data itself (to perform some analysis Change Analyst was coupled with other softwares i.e SPPS, Patch Analyst and ArcGIS), hence pushed changing data formats and locations which may be the source of some model outcomes' anomalies.

In addition, as a less temporal explicit modeling approach, LRM outputs probability maps contain information on where new developments will take place, but not when changes will occur (Cheng, 2003). LRM relies heavily on existing land cover/use history patterns (not urbanized areas with no history of land cover/use change). Hence, LRM meant for ideal situations (not absolutely real). A possible solution to deal with temporal dynamism, further researches would be combined with other model approaches like a CA model or other What If models (CommunityViz etc.). Results comparisons from different modeling approaches should be applied to point out weaknesses, strengths and a demand to reassess data and analysis procedures followed in one modeling approach or another (Lesschen et al., 2005). Such comparisons can enable to have information on Kigali city growth on various scales, which can help in turn, taking urban growth decisions at different levels of urban development planning. A part from limitations pointed out, the model outputs of this study will be taken as a tool for validating the proposed zoning in turn which will help in deciding where new infrastructures can be developed to meet the needs of the population in coming year.

\section{Acknowledgements}

The authors would like to acknowledge the support from NUFFIC for their financial facilitations. 
http://dx.doi.org/10.4314/rj.v1i1S.7D

\section{References}

Abebe, F. K. (2011). Modeling informal settlement growth in Dar es Salaam, Tanzania. University of Twente, Faculty of Geo-Information and Earth Observation (ITC). Retrieved from http://www.itc.n1/library/papers_2011/msc/upm/abebe.pdf

Abebe, G. A. (2013). Quantifying urban growth pattern in developing countries using remote sensing and spatial metrics: a case study in Kampala, Uganda. University of Twente, Faculty of Geo-Information and Earth Observation (ITC), Enschede. Retrieved from http://www.itc.nl/library/papers_2013/msc/upm/abebe.pdf

Aibinu, A. (2001). GIS Application in urban planning and urban management: Utilizing GIS in Kigali urban planning and city management. Vienna.

Arsanjani Jamal Jokar, Helbich, M., Kainz, W., \& Darvishi Boloorani, A. (2013). Integration of Logistic Regression, Markov chain and Cellular Automata models to simulate urban expansion. International Journal of Applied Earth Observation and Geoinformation, 21, 265-275. http://doi.org/10.1016/j.jag. 2011.12.014

Cheng, J. (2003). Modeling spatial and temporal of urban growth. Utrecht University. Retrieved from http://www.itc.n1/library/Papers_2003/phd_theses/cheng_jianquan.pdf

Civco, D. L., Chabaeva, A., Angel, S., \& Sheppard, S. (2005). The urban growth management initiative: Confronting the expected doubling of the size of cities in the developing countries in the next thirty yearsmethods and preliminary results. ASPRS 2005 Annual Conference. In Geospatial Goes Global: From Your Neighborhood to the Whole Planet. Baltimore, Maryland.

Dendoncker, N., Rounsevell, M., \& Bogaert, P. (2007). Spatial analysis and modeling of land use distributions in Belgium. Computers, Environment and Urban Systems, 31(2), 188-205. http://doi.org/10.1016/j.compenvurbsys.2006.06.004

Dong, R., Dong, J., Wu, G., \& Deng, H. (2006). Optimization of post-classification processing of high-resolution satellite image: A case study. Science in China Series E: Technological Sciences, 49(S1), 98-107. http://doi.org/10.1007/s11431-006-8111-3

Dubovyk, O., Sliuzas, R., \& Flacke, J. (2011). Spatio-temporal analysis of ISs development: A case study of Istanbul,Turkey. ISPRS Journal of Photogrammetry and Remote Sensing, 66(2), 234-246.

Duwal, S. (2013). Modeling urban growth in Kathmandu Valley. University of Twente, Enschede. Retrieved from http://www.itc.nl/library/papers_2013/msc/upm/duwal.pdf

Edaw, Architecture, O., Tech, T., ERA, \& Borders, E. without. (2007). Kigali Conceptual Master Plan. Denver, USA.

Field, A. (2013). Discovering statistics using SPSS. (3 rd editi). London, England: SAGE Publications.

Griffiths, P., Hostert, P., Gruebner, O., \& der Linden, S. van. (2010). Mapping megacity growth with multi-sensor data. Remote Sensing of Environment, 114(2), 426-439. http://doi.org/10.1016/j.rse.2009.09.012

Hu, Z. (2004). Modeling urban growth in the Atlanta, Georgia metropolitan area using Remote Sensing and GIS, Doctor of Philosophy thesis. University of Georgia,Athens, Georgia.

Hu, Z., \& Lo, C. P. (2007). Modeling urban growth in Atlanta using Logistic Regression. Computers Environment and Urban Systems, 31(6), 667-688.

Huang, B., Zhang, L., \& Wu, B. (2009). Spatiotemporal analysis of rural-urban land conversion. International Journal of Geographical Information Science, 23(3), 379-398. http://doi.org/10.1080/13658810802119685

J.Padmavathi. (2012). Logistic Regression in feature selection in data mining. International Journal of Scientific 
\& Engineering Research, 3(8, NaN-2012).

Koomen, E., \& Stillwell, J. (2007). Modeling land use theories and methods. In E. Koomen, J. Stillwell, A. Bakema, \& H. J. Scholten (Eds.), (Vol. 90). Dordrecht: Springer Netherlands. http://doi.org/10.1007/978-1-4020-56482

Lesschen, J. P., Verburg, P. H., \& Staal, S. J. (2005). Statistical methods for analyzing the spatial dimension of changes in land use and farming systems. Wageningen, the Netherlands.

Manirakiza, V. (2012). Urbanization issue in the era of globalization: Perspectives for urban planning in Kigali. In Fourth Annual conference proceedings, Social Studies for Community Cohesion and Sustainable Development, Del/P/H/E -Education for Community Cohesion.

Michelon, B. (2009). The local market in Kigali as controlled public space: Adaptation and resistance by local people to "modern city life" The PHD seminar on 19-20 March 2009. In Public Space and Neighbourhood Quality. Delft, The Netherlands.

Mohan, M. (2010). Geospatial Information for urban sprawl planning and policies implementation in developing Country's NCR region: A study of NOIDA city, India., (April), 11-16.

Moore., D. S., McCabe., G. P., \& Craig, B. A. (2009). Introduction to the practice of statistics. (6th ed.). New York: W.H. Freeman and company.

Munshi, T., Zuidgeest, M., Brussel, M., \& van Maarseveen, M. (2014). Logistic Regression and Cellular Automatabased modeling of retail, commercial and residential development in the city of Ahmedabad, India. Cities, 39, 68-86. http://doi.org/10.1016/j.cities.2014.02.007

NISR. (2012). Population and Housing Census. Kigali.

Nong, Y., \& Du, Q. (2011). Urban growth pattern modeling using Logistic Regression. Geo-Spatial Information Science, 14(1), 62-67. http://doi.org/10.1007/s11806-011-0427-x

O'Sullivan David, \& Torrent Paul. (2000). Cellular models of urban systems. Centre for Advanced Spatial Analysis (UCL) (Vol. 22). London.

Pullar, D., \& Pettit, C. (2003). Improving urban growth forecasting with Cellular Automata: a case study for Hervey Bay: The modeling and simulation society of Australia and New Zealand Inc. (MSSANZ). In International Congress on Modelling and Simulation (Vol. 4). Townsville, Australia.

REMA. (2013). Kigali state of environment and outlook report 2013. Kigali.

Rogerson, P. A. (2015). Statistical methods for geography: A student's guide. (R. Rojek, Ed.) (4th ed.). Berlin, Heidelberg: SAGE Publications Inc.

Surbana. (2012). Detailed Kigali City Master Plan, Rwanda: Vision Report, May 2012.

Treitz, P., \& Rogan, J. (2004). Remote sensing for mapping and monitoring land-cover and land-use change-an introduction. Progress in Planning, 61(4), 269-279. http://doi.org/10.1016/S0305-9006(03)00064-3

UN-HABITAT. (2011). World Population Prospects: The 2008 revision methodology of the United Nations population estimates and projections. New York.

Verburg, P. H., Eck, J. R. R. van, Nijs, T. C. M. de, Dijst, M. J., \& Schot, P. (2004). Determinants of land-use change patterns in the Netherlands. Environment and Planning B: Planning and Design, 31(1). http://doi.org/10.1068/b307

Viera, A. J., \& Garrett, J. M. (2005). Understanding interobserver agreement: the Kappa statistic. Family Medicine, 37(5), 360-3. Retrieved from http://www.ncbi.nlm.nih.gov/pubmed/15883903 